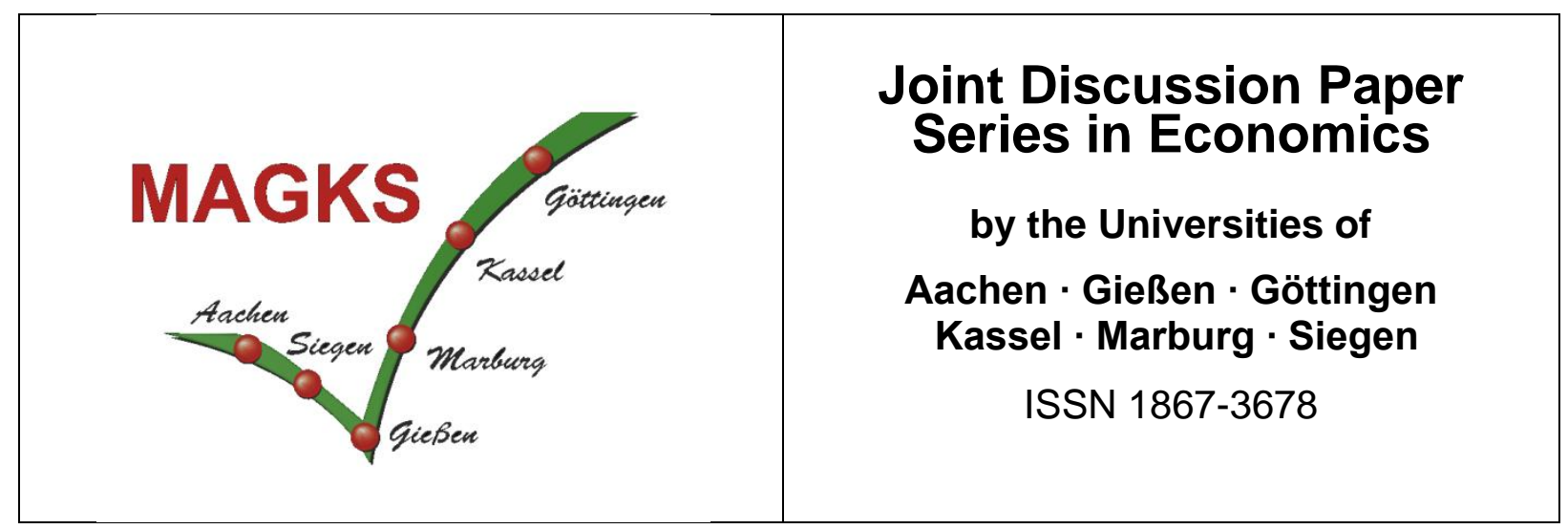

No. 38-2021

\title{
Marius Braun
}

\section{A Real-Option Analysis of Climate Change and International Migration}

This paper can be downloaded from:

https://www.uni-marburg.de/en/fb02/research-

groups/economics/macroeconomics/research/magks-ioint-discussion-papers-in-economics

Coordination: Bernd Hayo $•$ Philipps-University Marburg

School of Business and Economics - Universitätsstraße 24, D-35032 Marburg

Tel: +49-6421-2823091, Fax: +49-6421-2823088, e-mail: hayo@wiwi.uni-marburg.de 


\title{
A Real-Options Analysis of Climate Change and International Migration*
}

\author{
Marius Braun ${ }^{\dagger}$
}

November 9, 2021

\begin{abstract}
The potential impact of climate change on international migration patterns has recently received considerable attention in both the public and academic debate. Yet, much of the empirical literature fails to find increases in international migration due to climate change. The current paper attempts to resolve this "immobility paradox" by applying a real-options framework to the relationship between climate change and international migration. This framework suggests that individuals may postpone their migration response to climate change in the face of uncertainty and only migrate once impacts of climate change have exceeded certain thresholds. I test this prediction using semiparametric regression methods which allow me to empirically identify the threshold effects implied by the real-options framework. However, the findings are generally inconsistent with such threshold effects. Rather, the results suggest that in low-income countries, individuals' migration response is hampered by the existence of liquidity constraints. These are likely to become more binding due to climate change-induced decreases in agricultural productivity.
\end{abstract}

Keywords: climate change, international migration, real-options, semiparametric methods

JEL Codes: C14, F22, Q54

\footnotetext{
${ }^{*}$ I thank Bernd Hayo, Peter Tillmann, Johannes Zahner and the participants of the September 2021 MAGKS doctoral colloquium for helpful comments and discussion. I also thank Cornelia Strauß, Jürgen Meckl and Irina Hopp for valuable comments and suggestions.

${ }^{\dagger}$ Faculty of Economics and Business Studies, Justus Liebig University Gießen, Licher Straße 66, 35394 Gießen. Email: marius.braun-2@wirtschaft.uni-giessen.de
} 


\section{Introduction}

In its 2014 assessment report, the Intergovernmental Panel on Climate Change (IPCC) notes that recent impacts of climate change "reveal significant vulnerability and exposure of some ecosystems and many human systems to current climate variability" (IPCC 2014: 40). One potentially important adaptation response which has recently received increasing attention in both the public and academic debate is migration, both within countries and across borders. Yet, much of the empirical literature fails to observe increases in international migration due to climate change (e.g., Millock 2015; Burzynski et al. 2019; Bertoli et al. 2020; Hoffmann et

al. 2020). This finding is in contrast to the large-scale international movements frequently predicted to occur as a result of climate change (e.g., Myers 2005; Stern 2006).

The current paper attempts to resolve this "immobility paradox" (Beine, Noy and Parsons 2021) by applying a real-options framework to the relationship between climate change and international migration. First developed by Dixit (1992) and Dixit and Pindyck (1994), this framework has been applied extensively in the economic literature on migration (e.g., Burda 1995; O'Connell 1997; Anam, Chiang and Hua 2008; Moretto and Vergalli 2008; Gardner and Hendrickson 2018; Mense 2018) and suggests that migration is akin to an investment under uncertainty: Migration (in particular across borders) is typically associated with large unrecoverable costs; in addition, future conditions in both origin and destination locations are often highly uncertain. As a result, it may be optimal to postpone the migration decision in order to acquire more information about the economic environment.

Applied to the context of climate change and migration, this framework suggests that individuals may postpone their migration response to climate change and only migrate once impacts of climate change have exceeded certain thresholds (Mense 2018). Since such thresholds are likely much higher for international migration than for internal migration, the realoptions framework potentially explains some of the empirical evidence indicating that climate change-induced international migration is relatively uncommon. In this regard, the current paper relates to a large literature that employs a real-options approach to analyze invest- 
ments in climate change adaptation (Ginbo, Di Corato and Hoffmann 2021).

In addition, the current paper contributes to a growing body of research which empirically investigates internal and international migration responses to climate change, with much of the literature focusing on developing countries (see Cattaneo et al. (2019) for a more extensive review). One of the first studies to investigate the impact of changes in climatic conditions on internal migration is Barrios, Bertinelli and Strobl (2006). Using cross-country panel data for Sub-Saharan Africa, the authors find that decreases in rainfall are associated with an increase in urbanization rates. More recently, using panel data for 32 African countries, Henderson, Storeygard and Deichmann (2017) document a positive effect of declines in moisture on urbanization rates. Baez et al. (2017a; 2017b) find a similar effect for Latin American and Caribbean countries; in particular, they show that younger individuals have a higher propensity to migrate in response to droughts, hurricanes, and prolonged heat exposure. Although some other studies only observe modest effects of certain climatic factors on internal migration (e.g., Gray and Mueller (2012) and Mueller, Gray and Kosec (2014) for flooding in Bangladesh and Pakistan, respectively), the majority of studies find significant impacts of climate change on internal migration patterns.

However, empirical evidence on climate change-induced international migration is considerably more mixed. In their seminal paper, Marchiori, Maystadt and Schumacher (2012) find that temperature and precipitation anomalies affect international migration in Sub-Saharan Africa through both their impact on amenities and on wages in the agricultural sector. Cattaneo and Peri (2016), using a larger sample of 115 non-OECD countries, observe a positive relationship between average temperature and emigration rates, but only for middle-income countries. For low-income countries, on the other hand, the authors find a negative effect of average temperature on emigration rates. Drabo and Mbaye (2015) study the effect of natural disasters related to climate change on emigration rates in developing countries. They report significant positive effects of natural disasters on emigration, but only for individuals with high levels of education, suggesting that developing countries may experience brain 
drain effects due to climate change.

In contrast, several other studies find no evidence that climatic factors influence international migration patterns. Ruyssen and Rayp (2014), using panel data on migration flows between Sub-Saharan African countries, observe no significant impact of temperature anomalies on international migration. Beine and Parsons (2015) likewise find no evidence of direct effects of climatic factors on international migration; however, their results suggest that natural disasters induce internal migration in developing countries. Gröschl and Steinwachs (2017), using decennial panel data on bilateral migration flows, also fail to find significant effects of natural disasters on international migration. Overall, the literature suggests that changes in climatic variables are primarily associated with internal migration, in particular in developing countries, but not with international migration.

In order to empirically assess the real-options framework, I follow Burda et al. (1998) and Basile and Lim $(2006 ; 2017)$ and apply semiparametric regression methods developed by Hastie and Tibshirani (1986), which allow me to identify the nonlinear relationship between climate change and international migration implied by the framework. To the best of my knowledge, the current paper is the first to apply these methods to the climate-migration relationship. However, my findings are generally inconsistent with the real-options framework. Instead, the results are in line with the notion of "trapped populations" raised by recent literature (e.g., Cattaneo and Peri 2016; Beine and Parsons 2017; Gröschl and Steinwachs 2017; Cui and Feng 2020): Particularly in developing countries, individuals are unable to move due to liquidity constraints, which are likely aggravated by negative impacts of climate change on agricultural productivity.

The rest of the paper is organized as follows. Section 2 introduces a simple real-options framework of climate change and international migration. Section 3 describes the data and variables. Sections 4 and 5 present the empirical strategy and results, respectively. Section 6] shows some robustness checks, and Section 7 concludes. 


\section{Theoretical Framework}

Based on recent work by Gardner and Hendrickson (2018) and Mense (2018), in this section I present a specific application of the real-options framework that illustrates why it may be optimal for individuals to postpone their migration response to the impacts of climate change in the face of uncertainty. Consider a representative household who chooses whether to stay in their home country or migrate abroad. The quality of climatic conditions $c(t)$ with $c(0)=c_{0}$ evolves according to a geometric Brownian motion (GBM):

$$
d c=c(\mu d t+\sigma d z)
$$

where $\mu<0$ is a drift parameter capturing the long-term trend of the GBM, $\sigma$ is the standard deviation per unit of time and $d z$ is the increment of a Wiener process of the form $z(t)=\varepsilon(t) \sqrt{d t}$ with $\varepsilon(t) \sim \mathcal{N}(0,1)$. Equation (1) implies that $c$ changes gradually over time without discrete "jumps", which may apply quite well to a range of slow-onset climatic events such as temperature increase, drought and sea level rise (Mense 2018; Cattaneo et al. 2019). The GBM is characterized by a negative long-term trend (indicated by $\mu<0$ ) while there is uncertainty as to how $c$ evolves in the short term, i.e. although climatic conditions are deteriorating on average over time, there is a positive probability that they will improve in the next period (Gardner and Hendrickson 2018).

I assume that the household obtains a perpetual constant dividend $w$ if they choose to emigrate. $w$ could be thought of as an exogenous outside opportunity, reflecting the idea that

households may lack accurate information about the prospective destination country (Burda 1995). Migration is also associated with a fixed upfront cost $M>0$, which encompasses both monetary and psychological cost.

The household's Bellman equation can be expressed as

$$
r V(c)=c+\frac{1}{d t} \mathbb{E}[d V]
$$


where $r$ is the real interest rate (Dixit and Pindyck 1994: 101-105). If we apply Ito's Lemma, substitute the right-hand side of Equation (1) and take expectations, we obtain the following second-order partial differential equation:

$$
\frac{1}{2} \sigma^{2} c^{2} V^{\prime \prime}(c)+\mu c V^{\prime}(c)-r V(c)+c=0
$$

The solution of this differential equation is given by

$$
V(c)=A_{1} c^{\gamma_{1}}+A_{2} c^{\gamma_{2}}+V_{p}(c)
$$

with $A_{1} c^{\gamma_{1}}$ and $A_{2} c^{\gamma_{2}}$ as homogenous solutions and $V_{p}(c)$ as the particular solution. $A_{1}$ and $A_{2}$ are constants, and $\gamma_{1}$ and $\gamma_{2}$ are the solutions of the characteristic equation $\left(\sigma^{2} / 2\right) \gamma^{2}+$ $\left(\mu-\sigma^{2} / 2\right) \gamma-r=0$ :

$$
\begin{aligned}
& \gamma_{1}=\frac{1}{\sigma^{2}}\left[-\left(\mu-\frac{\sigma^{2}}{2}\right)-\sqrt{\left(\mu-\frac{\sigma^{2}}{2}\right)^{2}+2 \sigma^{2} r}\right]<0 \\
& \gamma_{2}=\frac{1}{\sigma^{2}}\left[-\left(\mu-\frac{\sigma^{2}}{2}\right)+\sqrt{\left(\mu-\frac{\sigma^{2}}{2}\right)^{2}+2 \sigma^{2} r}\right]>0
\end{aligned}
$$

The first two terms in Equation (4) represent the option value of migrating abroad, whereas $V_{p}(c)$ represents the value of staying in the home country.

Following Gardner and Hendrickson (2018), I impose two boundary conditions on this solution in order to solve the model. The first condition requires that the option value of migrating is reduced to zero as $c$ tends to infinity, i.e. there is no incentive to migrate if the quality of climatic conditions is sufficiently high:

$$
\lim _{c \rightarrow \infty}\left[V(c)-V_{p}(c)\right]=0
$$

Since $\gamma_{2}$ is positive, Equation (6) implies that $A_{2}=0$. The second condition, also known as 
the "value-matching" condition, then requires that the value function $V(c)$ be equal to the present value associated with migrating abroad $w / r$ less the cost of migration $M$ :

$$
\begin{array}{r}
V\left(c^{*}\right)=A_{1} c^{* \gamma_{1}}+V_{p}\left(c^{*}\right)=\frac{w}{r}-M \\
\Longleftrightarrow A_{1}=\left(c^{*}\right)^{-\gamma_{1}}\left[\frac{w}{r}-M-V_{p}\left(c^{*}\right)\right]
\end{array}
$$

where $c^{*}$ denotes the quality of climatic conditions at which it is optimal to migrate. Put differently, this condition implies that migration is optimal when the household is indifferent between migrating and staying. Substituting $A_{1}$ back into Equation (4), we obtain

$$
V(c)=\left(\frac{c}{c^{*}}\right)^{\gamma_{1}}\left[\frac{w}{r}-M-V_{p}\left(c^{*}\right)\right]+V_{p}(c)
$$

Choosing a lower value of $c^{*}$, which implies that the household will on average have to wait longer before migrating, lowers the value of $V_{p}\left(c^{*}\right)$, thus increasing the present value of the net benefit of migration $V(c)$. On the other hand, a lower $c^{*}$ increases the stochastic discount factor $\left(c / c^{*}\right)^{\gamma_{1}}$, thus reducing $V(c)$. The household therefore chooses $c^{*}$ such as to maximize $V(c)$.

The first-order condition is given by

$$
-\gamma_{1}\left[\frac{w}{r}-M-V_{p}\left(c^{*}\right)\right]=c^{*} V_{p}^{\prime}\left(c^{*}\right)
$$

As previously noted, the particular solution represents the present discounted value of staying in the home country, i.e.

$$
V_{p}(c)=\frac{c}{r-\mu}
$$

$c^{*}$ is thus given by

$$
c^{*}=\left(\frac{\gamma_{1}}{\gamma_{1}-1}\right)(r-\mu)\left[\frac{w}{r}-M\right]
$$

The model provides two clear predictions: First, migration will only occur once the quality 
of climatic conditions falls below $c^{*}$, that is, once adverse impacts of climate change have exceeded certain thresholds. Second, $c^{*}$ negatively depends on migration $\operatorname{costs} M$; in other words, the household is willing to endure a lower quality of climatic conditions before migrating the higher the cost of migration are. The intuition behind this prediction is the following (Mense 2018; Ginbo, Di Corato and Hoffmann 2021): Because migration is costly and to a certain extent irreversible and information about climatic conditions is revealed gradually, it is valuable to postpone the migration decision; this incentive is greater the higher the costs of migration are. However, once climatic conditions deteriorate past a critical level, the household will no longer be better off waiting and choose to migrate instead.

A number of limitations of the model should be noted. First, as mentioned above, due to the nature of the GBM, the model only applies to gradual changes in climatic conditions and may thus not be suited to capture the effects of fast-onset climatic events such as storms, flooding or extreme heat on international migration. Such events may be modeled more appropriately using Poisson processes (as done, e.g., by Abadie, Sainz de Murieta and Galarraga (2017)). Incorporating this type of process would present an interesting extension of the model; in the current paper, however, I will instead focus on slow-onset climatic events such as drought and temperature increase and leave these considerations for future research.

Second, the fact that climate-induced international migration appears to be relatively uncommon may also be consistent with a number of alternative explanations. In particular, as noted by Cattaneo and Peri (2016), this result may be generated by liquidity constraints faced by households in their countries of origin, i.e. households may simply lack the resources to finance the costs of migration. For now, the available data does not allow me to determine the exact mechanism behind a potential threshold effect. However, if households do make their migration decisions according to an option value of waiting rule, I should observe the corresponding threshold to be lower in low-income countries than in middle-income countries since liquidity constraints are likely more relevant in the former. Similarly, from Equation (11) I should expect the threshold level of quality of climatic conditions to be higher for 


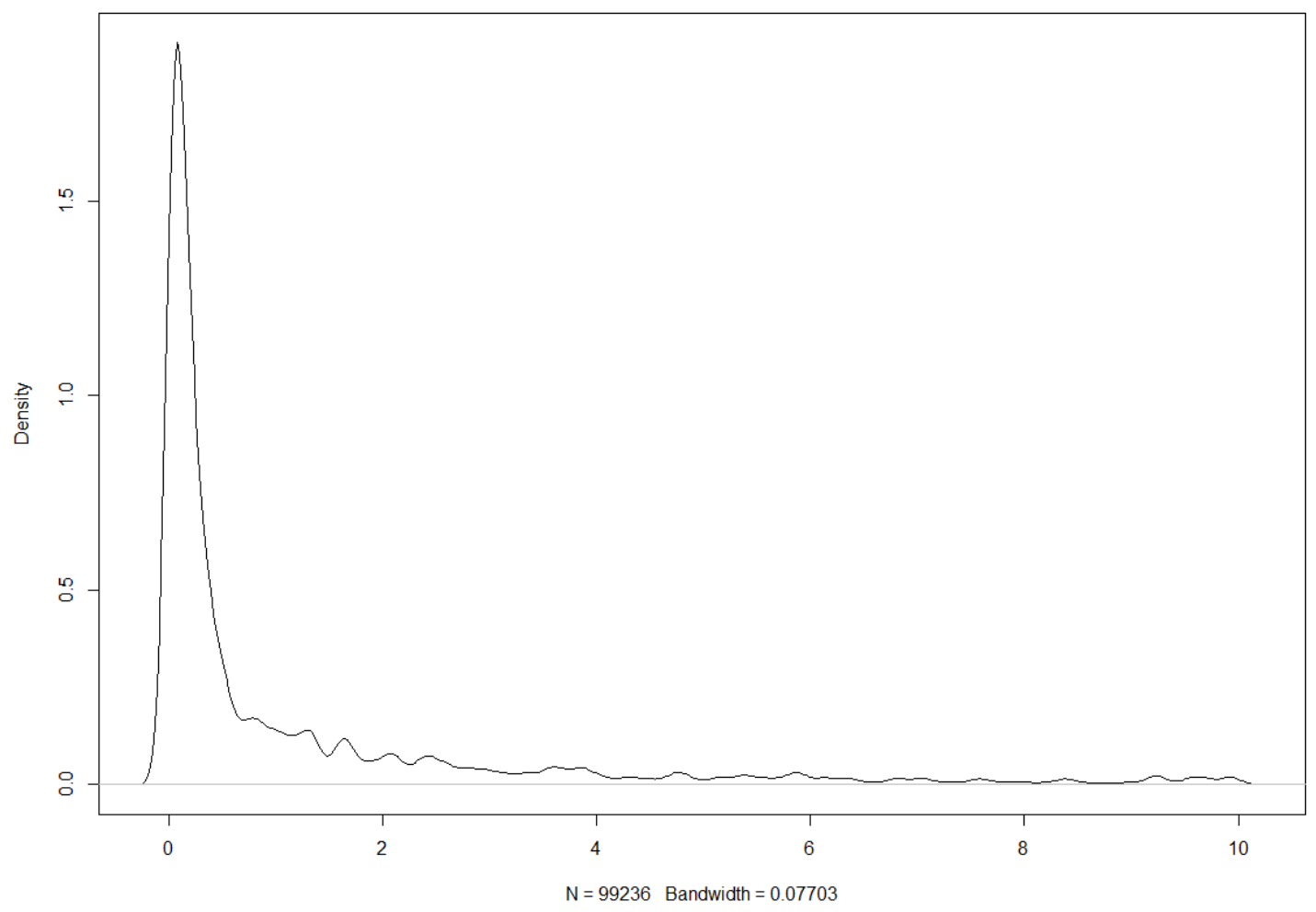

Figure 1: Kernel density estimation of bilateral migration rates

migration to close destinations than to more distant ones due to lower migration costs.

\section{Data}

Data on bilateral international migration flows is taken from Abel and Sander (2014). Based on international migrant stock tables published by the United Nations' Department of Economic and Social Affairs (UN 2013), the dataset provides information on bilateral migration flows between 196 countries over five-year intervals from 1990 to 2010. The dataset thus allows me to include middle- and low-income countries as both origins and destinations, which is an advantage over other datasets such as Ortega and Peri (2013), Vezzoli, Villares-Varela and de Haas (2014) and Wesselbaum and Aburn (2019) which only include OECD countries as destinations.

Data on monthly mean temperature and precipitation is taken from version 4.05 of the 
Table 1: Summary statistics

\begin{tabular}{|c|c|c|c|c|c|c|}
\hline \multirow{2}{*}{$\begin{array}{l}\text { Countries included in the sample } \\
\text { Variable }\end{array}$} & \multicolumn{3}{|c|}{ Non-OECD middle-income countries } & \multicolumn{3}{|c|}{ Non-OECD low-income countries } \\
\hline & Obs & Mean & Std. dev. & Obs & Mean & Std. dev. \\
\hline Emigration rate $(\%)$ & 81120 & 0.013 & 0.1595 & 26520 & 0.0099 & 0.1813 \\
\hline Temperature deviation $\left({ }^{\circ} \mathrm{C}\right)$ & 416 & 0.6333 & 0.3668 & 136 & 0.5690 & 0.3619 \\
\hline Precipitation deviation (mm/year) & 416 & -133.32 & 143.83 & 136 & -162.99 & 129.98 \\
\hline GDP per capita in 1990 (2017 US\$) & 104 & 11742.09 & 15054.78 & 34 & 1285.22 & 379.83 \\
\hline Emigration rate to neighboring countries (\%) & 1080 & 0.1351 & 0.5138 & 472 & 0.2479 & 1.1107 \\
\hline Emigration rate to non-neighboring countries (\%) & 80040 & 0.0112 & 0.1484 & 26048 & 0.0056 & 0.1006 \\
\hline Emigration rate to OECD countries (\%) & 13312 & 0.0217 & 0.1551 & 4352 & 0.0086 & 0.1022 \\
\hline Emigration rate to non-OECD countries (\%) & 67808 & 0.0111 & 0.1603 & 22168 & 0.0101 & 0.1931 \\
\hline
\end{tabular}

gridded climate dataset created by the Climatic Research Unit of the University of East Anglia (Harris et al. 2020). The original data are gridded to a $0.5^{\circ}$ latitude by $0.5^{\circ}$ longitude grid and are then aggregated to area-weighted country-level averages. I use the monthly observations to calculate annual averages, and then use the annual averages to calculate five-year averages corresponding to the five-year periods of the migration data. As argued by Beine and Parsons $(2015 ; 2017)$, using absolute levels of temperature and precipitation is not appropriate because these variables would not adequately capture how individuals respond to deviations from standard climatic conditions. Therefore, I compute temperature and precipitation anomalies as the deviation of countries' five-year averages from their respective 1901-1970 averages.

Information on GDP per capita is obtained from the World Development Indicators (World Bank 2021), Penn World Tables (Feenstra, Inklaar and Timmer 2015) and the World Economic Outlook Database (IMF 2021). The data on country population is taken from the World Development Indicators (World Bank 2021). Drawing from the migration data, I compute bilateral migration rates as the ratio between the migration flow from origin country $i$ to destination country $j$ during five-year period $t$ and the population of $i$ at the beginning of $t$. Figure 1 shows the kernel density estimation for bilateral migration rates, which reveals that the distribution of this variable is heavily right-skewed ${ }^{1}$.

Table 1 presents summary statistics. Following Cattaneo and Peri (2016) and Beine and

\footnotetext{
${ }^{1}$ Only for the purpose of the kernel density estimation shown in Figure 1 , I have scaled bilateral migration rates by a factor of $10^{6}$ and excluded observations greater than 10 .
} 
Parsons (2017), I only include non-OECD countries as countries of origin and distinguish between middle-income and low-income countries, where low-income countries are defined as those countries in the bottom quartile of the distribution of (purchasing power parityadjusted) GDP per capita in the year 1990. The resulting final sample includes 138 countries of origin, 34 of which are classified as low-income countries according to the above definition, while the remaining 104 are classified as middle-income countries (see the lists of low- and middle-income countries in the Appendix).

I observe that middle-income countries have a higher average emigration rate than lowincome countries. Consistent with previous literature (e.g., Oezden et al. 2011), the majority of migration from non-OECD countries can be attributed to migration flows to other nonOECD countries, which account for $76.4 \%$ of the migration flow volume between 1990 and 2010. In addition, although migration flows between neighboring countries comprise only $1.4 \%$ of observations in the sample, they account for $28.8 \%$ of the migration flow volume? This pattern is also reflected in the average migration rates to neighboring countries, which are an order of magnitude larger than migration rates to non-neighboring countries.

\section{Empirical Strategy}

To identify the nonlinear effects of climate on international migration implied by the realoptions framework, I follow Burda et al. (1998) and Basile and Lim (2006; 2017) and apply semiparametric regression techniques. More specifically, in light of the heavily skewed distribution of bilateral migration rates, I choose to estimate a generalized additive model (GAM) with Gamma distribution (for more details see Wood 2017):

$$
g\left(\mathbb{E}\left(y_{i j t}\right)\right)=\log \left(\mathbb{E}\left(y_{i j t}\right)\right)=\beta_{0}+s_{1}\left(T_{i t}\right)+s_{2}\left(P_{i t}\right)+\phi_{i}+\phi_{j}+\phi_{t}
$$

\footnotetext{
${ }^{2}$ Information on geographic contiguity is obtained from version 3.2 of the Direct Contiguity dataset (Stinnett et al. 2002).
} 
where $y_{i j t}$ is the bilateral migration rat ${ }^{3}$ from origin country $i$ to destination country $j$ in five-year period $t$ and is assumed to follow a Gamma distribution. $g\left(\mathbb{E}\left(y_{i j t}\right)\right)=\log \left(\mathbb{E}\left(y_{i j t}\right)\right)$ is the so-called canonical link function, which relates the expected value of $y_{i j t}$ to the explanatory variables. $s_{1}\left(T_{i t}\right)$ and $s_{2}\left(P_{i t}\right)$ are unknown smooth functions of the temperature and precipitation anomaly in origin country $i$ in five-year period $t$, respectively, which are estimated using penalized cubic regression splines (Wood 2017). As suggested by Wood (2011), smoothing parameters for the estimated functions $\hat{s}_{1}\left(T_{i t}\right)$ and $\hat{s}_{2}\left(P_{i t}\right)$ are selected using the restricted maximum likelihood (REML) method, which is implemented in the $\mathrm{R}$ package mgcv (Wood 2001). $\phi_{i}$ and $\phi_{j}$ are sets of origin and destination country fixed effects, respectively, in order to control for unobserved heterogeneity at the origin and destination country level, and $\phi_{t}$ is a set of time fixed effects.

Following recent literature (Dell, Jones and Olken 2014; Cattaneo and Peri 2016; Beine and Parsons 2017; Cattaneo and Bosetti 2017), I choose a parsimonious specification that includes fixed effects but no additional control variables such as GDP per capita, population, quality of institutions or probability of conflicts. As argued by these authors, those variables are likely themselves affected by changes in climatic conditions, and thus including them in the regression may result in an over-controlling problem, leading to biased estimates of the effects of climate on migration.

\section{Results}

\subsection{Main Results}

Table 2 presents my main results. I separately estimate semiparametric GAMs for low-income and middle-income countries, in which temperature and precipitation anomalies enter via nonparametric smooth functions. Column 1 reports the effective degrees of freedom (edf)

\footnotetext{
${ }^{3}$ To address the issue of zero flows, I follow Cai et al. (2016) and add one to all migration flows before computing emigration rates.
} 
Table 2: Main results

(1)

Low-income countries Middle-income countries

\begin{tabular}{lcc} 
Smooth terms & $e d f$ & $e d f$ \\
\hline $\mathrm{s}(\mathrm{T})$ & $8.491^{* * *}$ & $7.173^{* *}$ \\
& $(0.000)$ & $(0.046)$ \\
$\mathrm{s}(\mathrm{P})$ & $8.646^{* * *}$ & 6.903 \\
& $(0.000)$ & $(0.109)$ \\
REML score & -210953.1 & -554534.6 \\
$\mathrm{AIC}$ & -421953.6 & -1109366 \\
$\mathrm{~N}$ & 26520 & 81120 \\
Pseudo-R & 0.541 & 0.414 \\
\hline
\end{tabular}

Note: Time period: 1990-2010. Approximate p-values in parentheses. edf: effective degrees of freedom, REML: restricted maximum likelihood, AIC: Akaike information criterion. ${ }^{*} p<0.1,{ }^{* *} p<0.05,{ }^{* *} p<0.01$.

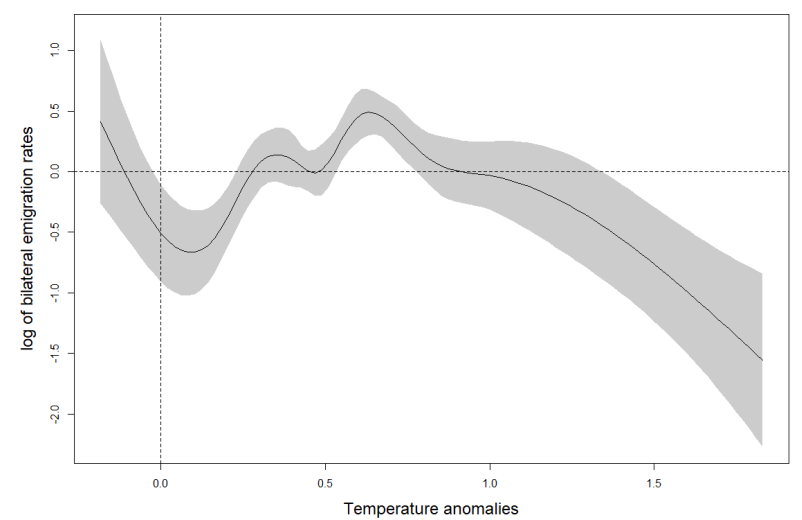

(a) Temperature, low-income countries

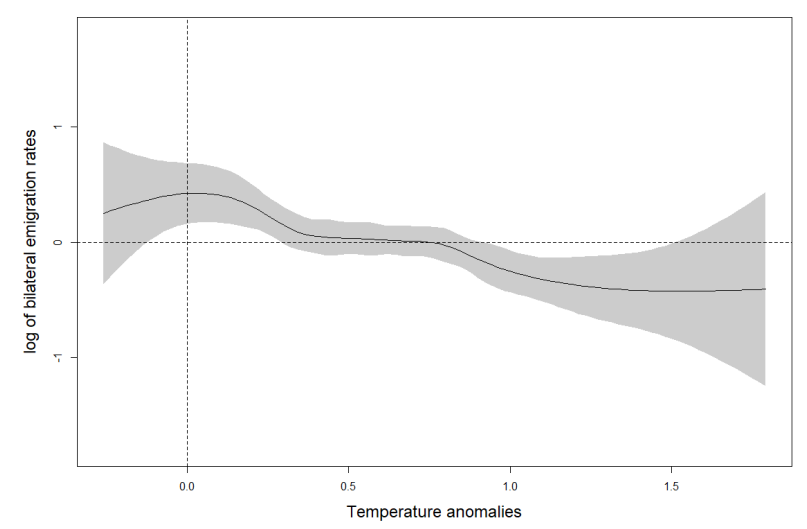

(c) Temperature, middle-income countries

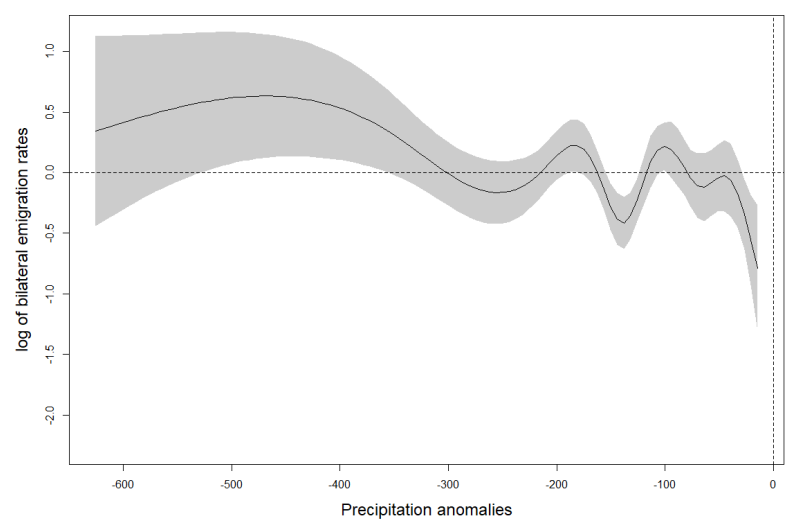

(b) Precipitation, low-income countries

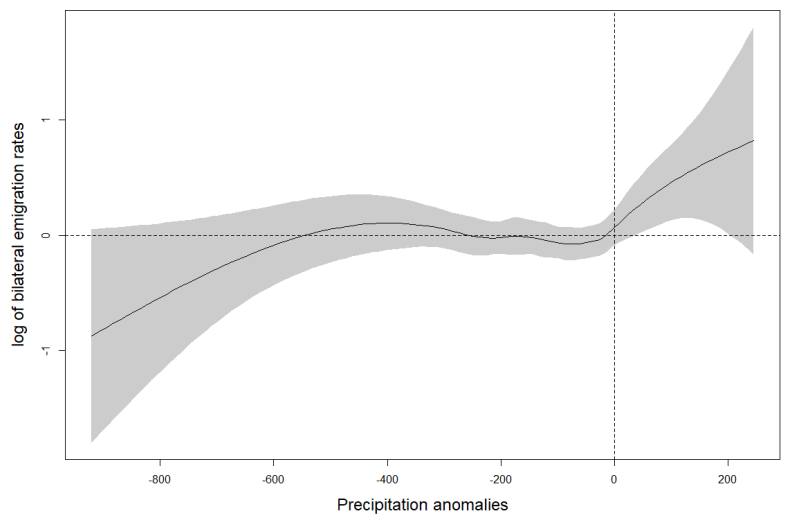

(d) Precipitation, middle-income countries

Figure 2: Nonlinear effects of temperature and precipitation anomalies on migration 
of the estimated smooth functions for low-income countries, while Column 2 reports the edf for middle-income countries. The edf indicate the degree of nonlinearity or "wiggliness" of the function, with an edf of 1 corresponding to a linear relationship. Both models include origin, destination and time fixed effects.

I find significant nonlinear effects of temperature and precipitation anomalies for lowincome countries and a significant effect of temperature anomalies for middle-income countries. This result is corroborated by $\chi^{2}$ difference tests comparing the GAM with a generalized linear model where temperature and precipitation anomalies enter linearly, which indicate that for both low-income and middle-income countries the GAM fits the data better than a linear specification. Figure 2 shows the estimated effects of temperature and precipitation anomalies on the log of bilateral migration rates with $95 \%$ Bayesian confidence intervals (Marra and Wood 2012). For low-income countries, I find a positive effect of temperature anomalies between 0.1 and $0.6{ }^{\circ} \mathrm{C}$ on migration (shown in Figure 2a), which then becomes negative for the remaining range of data. Figure $2 \mathrm{~b}$, on the other hand, shows no clear relationship between precipitation anomalies and migration for low-income countries; anomalies lower than approximately $-450 \mathrm{~mm} /$ year appear to have a negative effect on migration, but confidence intervals are quite large for this part of the sample. For middle-income countries, the GAM estimates a flat relationship between temperature anomalies and migration for most of the data range (see Figure 2c). Finally, Figure 2d shows that migration increases for positive precipitation anomalies and decreases for negative anomalies lower than about $-400 \mathrm{~mm} /$ year, but the effect is not statistically significant.

Overall, the findings are not in line with the threshold effect suggested by the real-options framework, which would be verified empirically if the model estimated a flat relationship for low levels of climatic anomalies and a positive relationship past certain thresholds (Basile and Lim 2017). Instead, the observed negative effect of temperature anomalies on migration in low-income countries is consistent with the role of liquidity constraints as emphasized by recent literature (e.g., Cattaneo and Peri 2016; Beine and Parsons 2017; Gröschl and 
Table 3: Specific emigration patterns: contiguity

\begin{tabular}{lcc}
\hline & $(1)$ & $(2)$ \\
Smooth terms & Low-income countries & Middle-income countries \\
& $e d f$ & $e d f$ \\
\hline $\mathrm{s}(\mathrm{T})$ & $8.360^{* * *}$ & 8.251 \\
& $(0.000)$ & $(0.125)$ \\
$\mathrm{s}\left(\mathrm{T}^{*}\right.$ contiguity) & $8.704^{* *}$ & $4.467^{* *}$ \\
& $(0.032)$ & $(0.018)$ \\
$\mathrm{s}(\mathrm{P})$ & $8.630^{* * *}$ & 8.749 \\
& $(0.000)$ & $(0.064)$ \\
$\mathrm{s}\left(\mathrm{P}^{*}\right.$ contiguity) & $8.636^{* * *}$ & 6.128 \\
& $(0.001)$ & $(0.905)$ \\
$\mathrm{REML} \mathrm{score}$ & -213845.5 & -563117.8 \\
$\mathrm{AIC}$ & -427827.6 & -1126614 \\
$\mathrm{~N}$ & 26520 & 81120 \\
Pseudo- $\mathrm{R}^{2}$ & 0.609 & 0.496 \\
\hline
\end{tabular}

Note: Time period: 1990-2010. Approximate p-values in parentheses. edf: effective degrees of freedom, REML: restricted maximum likelihood, AIC: Akaike information criterion. ${ }^{*} p<0.1,{ }^{* *} p<0.05,{ }^{* * *} p<0.01$.

Steinwachs 2017; Cui and Feng 2020): Increases in average temperature increase households' incentives to emigrate; past a certain threshold, however, tightening liquidity constraints due to worsening agricultural productivity dominate, as households are less able to afford the cost of migration, resulting in a negative effect on migration. The findings thus suggest that rather than employing a "wait and see" strategy, households in these countries may become "trapped" in place due to the adverse impacts of climate change.

\subsection{Migration to Neighboring Countries}

In the previous subsection, I demonstrated nonlinear relationships between temperature and precipitation anomalies and international migration that cannot be explained by the realoptions framework but are in part consistent with the existence of liquidity constraints. However, such constraints should matter to a lesser extent for migration to nearby destinations (Beine and Parsons 2017), and thus the real-options framework potentially does a better job at explaining migration to those destinations. Therefore, in this subsection I fol- 


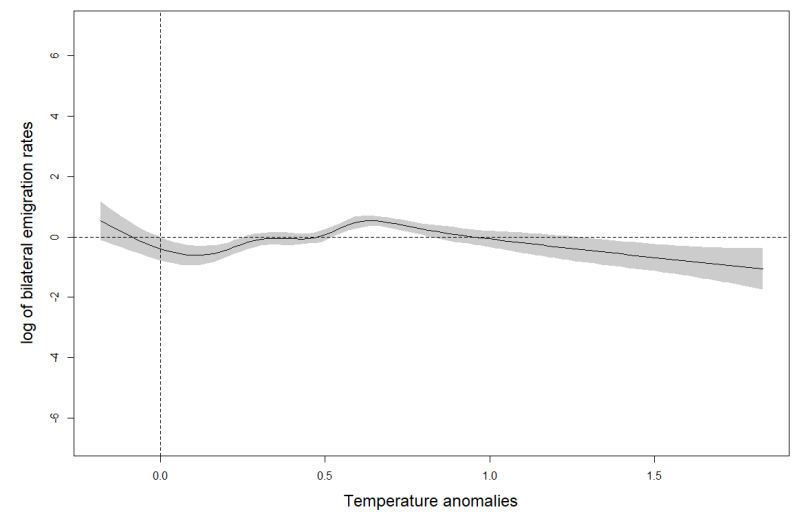

(a) Temperature and migration to nonneighboring countries

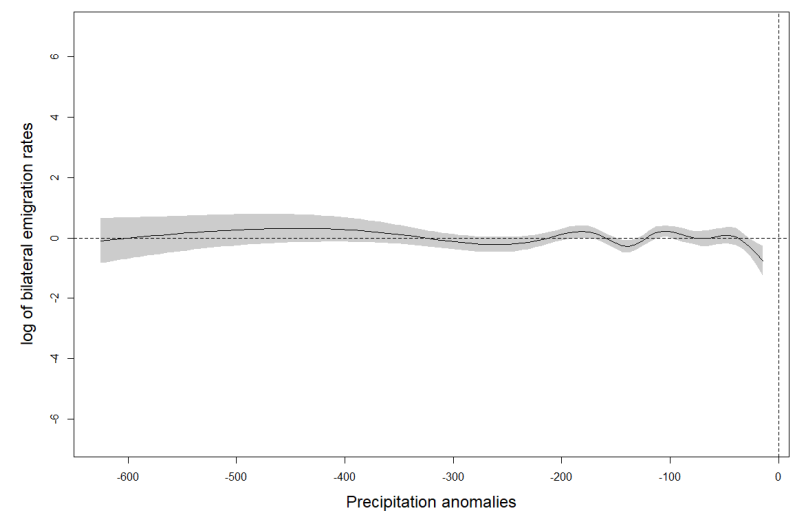

(c) Precipitation and migration to nonneighboring countries

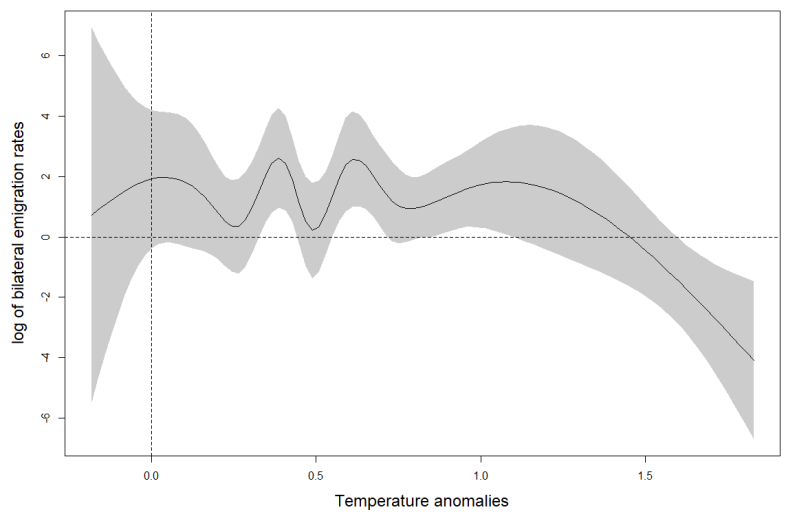

(b) Temperature and migration to neighboring countries

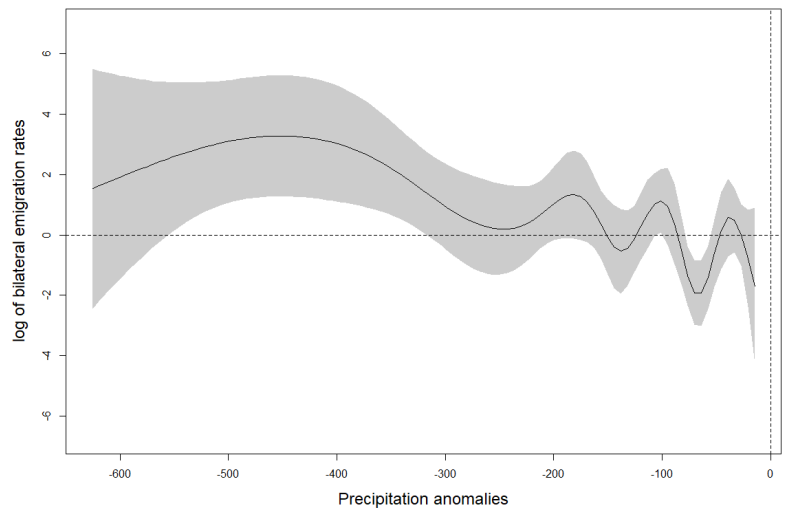

(d) Precipitation and migration to neighboring countries

Figure 3: Nonlinear effects of temperature and precipitation anomalies on migration from low-income countries to neighboring and nonneighboring countries 


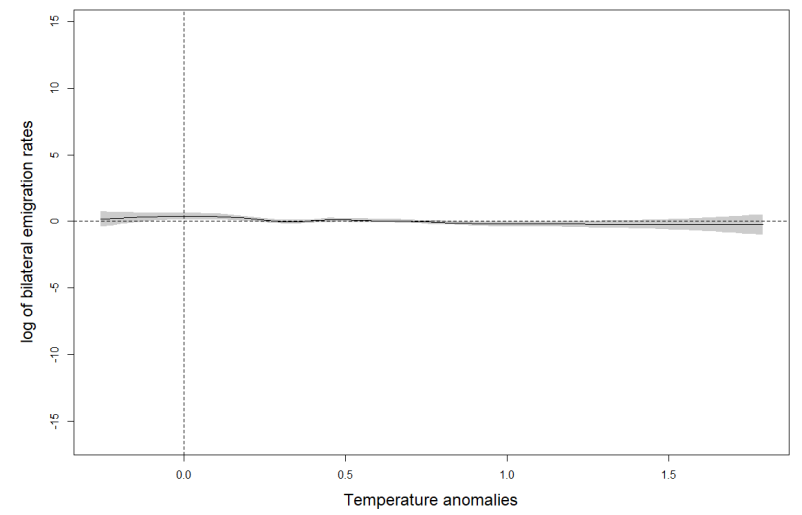

(a) Temperature and migration to nonneighboring countries

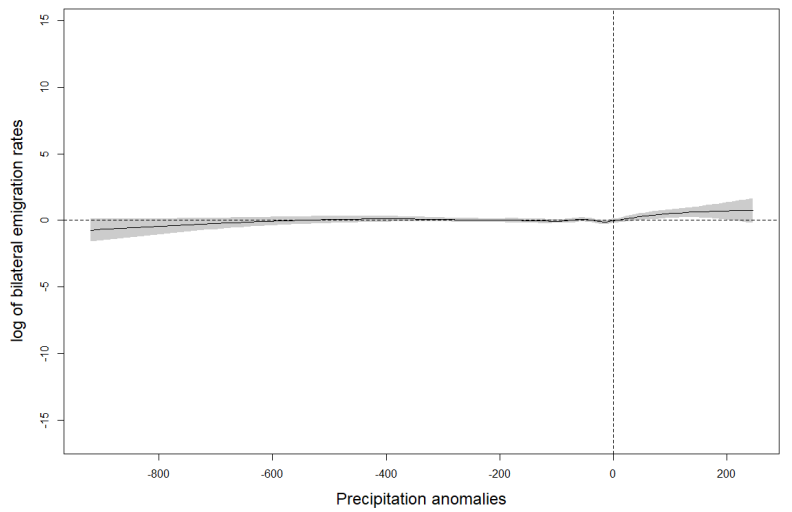

(c) Precipitation and migration to nonneighboring countries

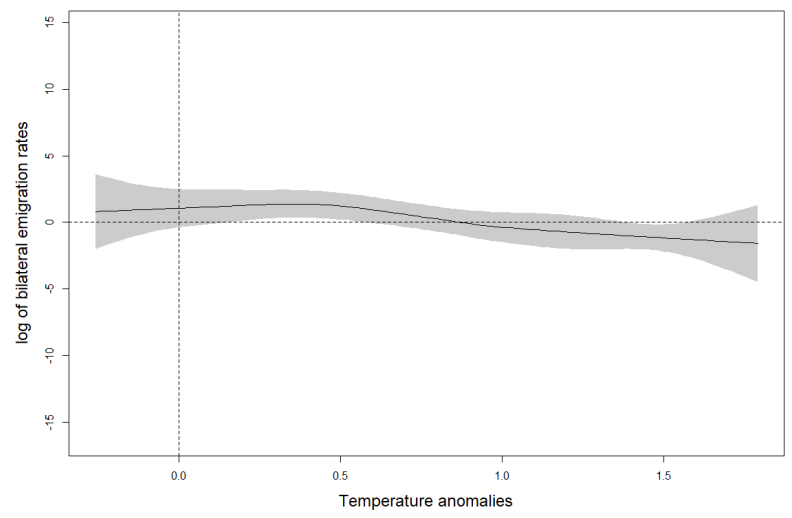

(b) Temperature and migration to neighboring countries

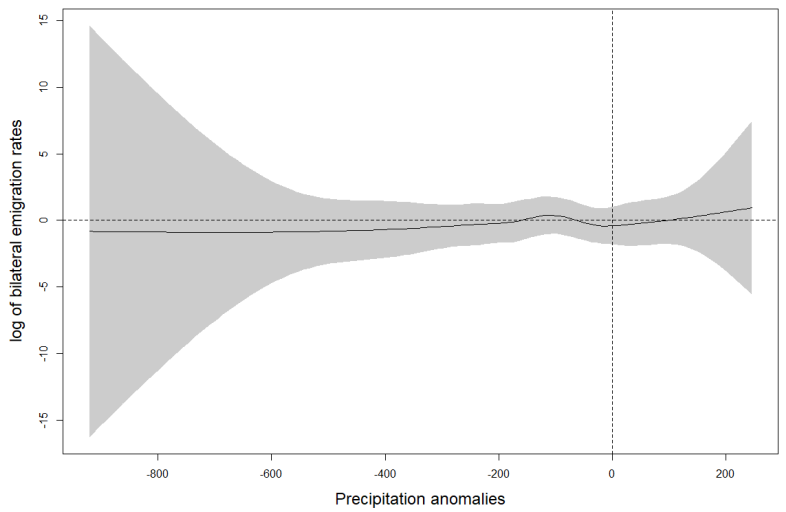

(d) Precipitation and migration to neighboring countries

Figure 4: Nonlinear effects of temperature and precipitation anomalies on migration from middle-income countries to neighboring and nonneighboring countries 
low Beine and Parsons (2017) and interact my measures of climatic anomalies with a dummy variable indicating whether the origin and destination countries are contiguous (i.e. share a common border) or not, resulting in the following model:

$$
g\left(\mathbb{E}\left(y_{i j t}\right)\right)=\log \left(\mathbb{E}\left(y_{i j t}\right)\right)=\beta_{0}+s_{1}\left(T_{i t}\right)+s_{1}\left(C_{i j} T_{i t}\right)+s_{2}\left(P_{i t}\right)+s_{2}\left(C_{i j} P_{i t}\right)+\phi_{i}+\phi_{j}+\phi_{t}
$$

where $C_{i j}$ is equal to one if $i$ and $j$ are contiguous and zero otherwise.

The results are reported in Table 3. For low-income countries, I find significant effects of temperature and precipitation anomalies for both neighboring and nonneighboring countries; again, edf between 8.3 and 8.7 indicate that the relationships are highly nonlinear. For middle-income countries, I only find a significant effect of temperature anomalies on migration to neighboring countries. Compared to the main results, pseudo- $\mathrm{R}^{2}$ values for models (1) and (2) increase from 0.541 to 0.609 and from 0.414 to 0.496 , respectively, suggesting that including interaction terms for contiguity increases the explanatory power of the GAM for both low- and middle-income countries.

Figures 3 and 4 plot the estimated effects for low- and middle-income countries, respectively. The upper and lower left panes of Figure 3 show flat relationships between climatic anomalies and migration from low-income countries to nonneighboring destination countries. Figure $3 \mathrm{~b}$ shows no clear relationship between temperature anomalies and migration to neighboring countries until approximately $1.1^{\circ} \mathrm{C}$; for values higher than that, migration decreases with temperature anomalies. Note, however, that this threshold is substantially higher than the value found in Figure 2a, which is in line with the idea that liquidity constraints hinder migration from low-income countries in response to climate change. Likewise, there is no clear relationship between precipitation anomalies and migration to neighboring countries (shown in Figure 3d) until about $-450 \mathrm{~mm} /$ year, beyond which the relationship becomes negative. For middle-income countries, the GAM estimates flat relationships between climatic anomalies and migration to both neighboring and nonneighboring countries (shown 
Table 4: Specific emigration patterns: OECD destination countries

\begin{tabular}{|c|c|c|}
\hline Smooth terms & $\begin{array}{c}(1) \\
\text { Low-income countries } \\
\text { edf }\end{array}$ & $\begin{array}{c}(2) \\
\text { Middle-income countries } \\
\text { edf }\end{array}$ \\
\hline $\mathrm{s}(\mathrm{T})$ & $\begin{array}{c}8.480^{* * *} \\
(0.000)\end{array}$ & $\begin{array}{c}7.958^{* * *} \\
(0.002)\end{array}$ \\
\hline $\mathrm{s}\left(\mathrm{T}^{*} \mathrm{OECD}\right.$ destination $)$ & $\begin{array}{c}4.325^{* * * *} \\
(0.000)\end{array}$ & $\begin{array}{c}8.413^{* * *} \\
(0.001)\end{array}$ \\
\hline $\mathrm{s}(\mathrm{P})$ & $\begin{array}{c}8.624^{* * *} \\
(0.000)\end{array}$ & $\begin{array}{l}7.692^{* *} \\
(0.028)\end{array}$ \\
\hline $\mathrm{s}\left(\mathrm{P}^{*} \mathrm{OECD}\right.$ destination $)$ & $\begin{array}{c}6.401 \\
(0.663)\end{array}$ & $\begin{array}{c}8.056^{* * *} \\
(0.000)\end{array}$ \\
\hline REML score & -211003 & -554867.4 \\
\hline $\mathrm{AIC}$ & -422062.5 & -1110087 \\
\hline $\mathrm{N}$ & 26520 & 81120 \\
\hline Pseudo- $\mathrm{R}^{2}$ & 0.543 & 0.418 \\
\hline
\end{tabular}

Note: Time period: 1990-2010. Approximate p-values in parentheses. edf: effective degrees of freedom, REML: restricted maximum likelihood, AIC: Akaike information criterion. ${ }^{*} p<0.1,{ }^{* *} p<0.05,{ }^{* * *} p<0.01$.

in Figure 4).

\subsection{Migration to OECD countries}

The results presented in the previous subsection suggest that even for migration to neighboring countries, for which liquidity constraints are likely to be less binding, the real-options framework does not explain migratory responses to climate change. In this subsection, I further investigate specific emigration patterns by differentiating between emigration to OECD and non-OECD destination countries. Analogous to Equation (13), I estimate the following model:

$$
\begin{array}{r}
g\left(\mathbb{E}\left(y_{i j t}\right)\right)=\log \left(\mathbb{E}\left(y_{i j t}\right)\right)=\beta_{0}+s_{1}\left(T_{i t}\right)+s_{1}\left(O E C D_{j} T_{i t}\right)+s_{2}\left(P_{i t}\right) \\
+s_{2}\left(O E C D_{j} P_{i t}\right)+\phi_{i}+\phi_{j}+\phi_{t}
\end{array}
$$




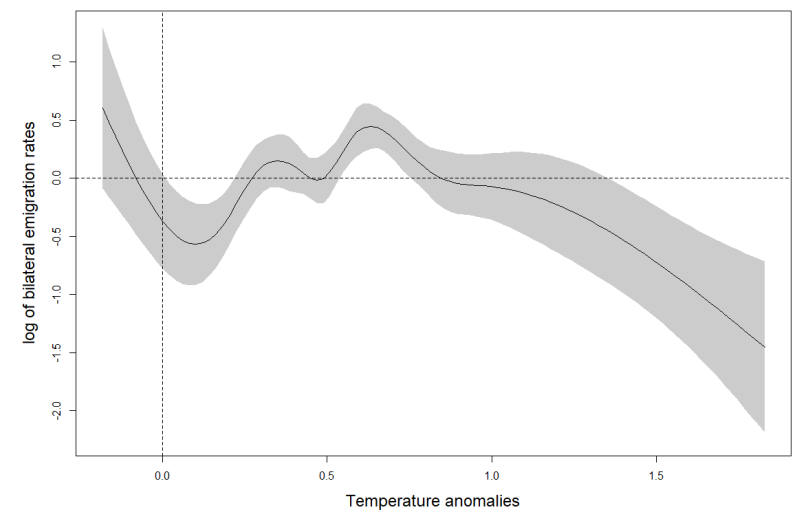

(a) Temperature and migration to non-OECD countries

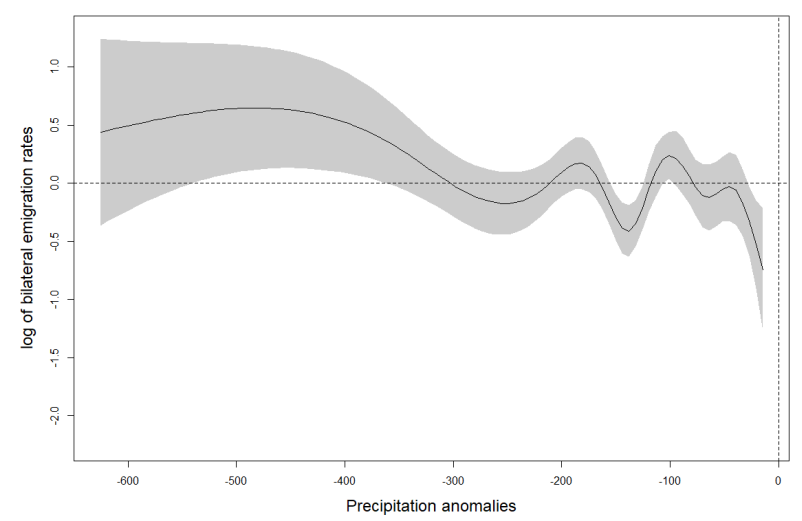

(c) Precipitation and migration to non-OECD countries

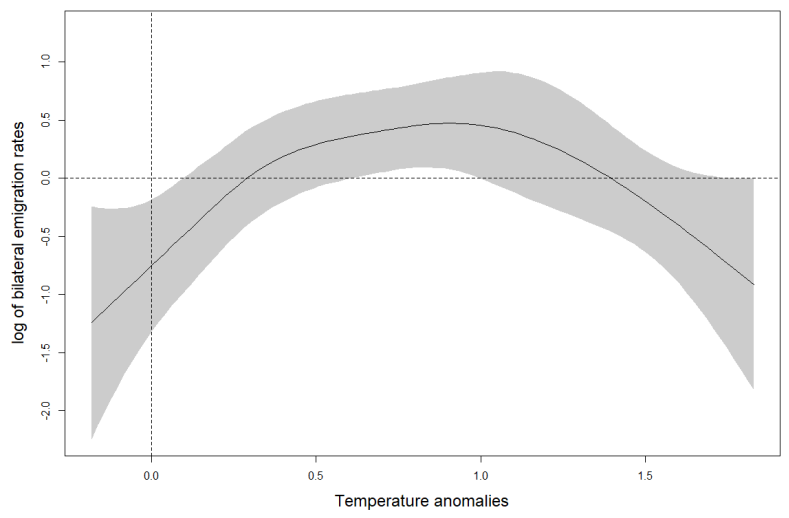

(b) Temperature and migration to OECD countries

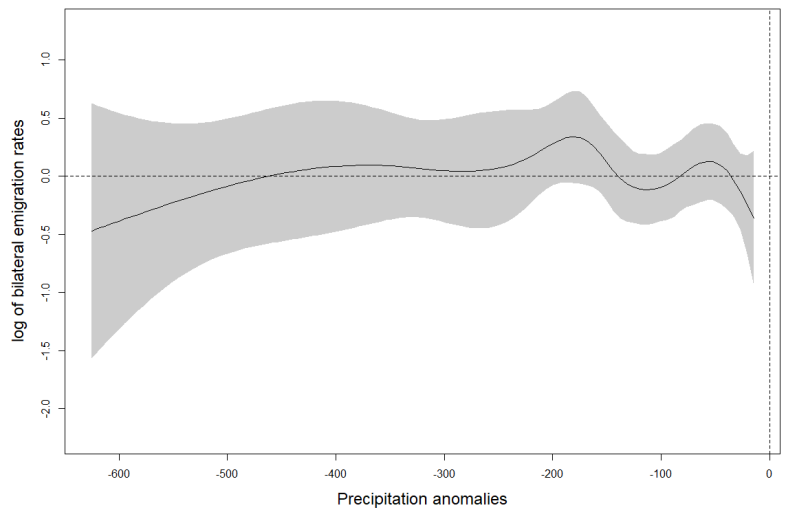

(d) Precipitation and migration to OECD countries

Figure 5: Nonlinear effects of temperature and precipitation anomalies on migration from low-income countries to OECD and non-OECD countries 

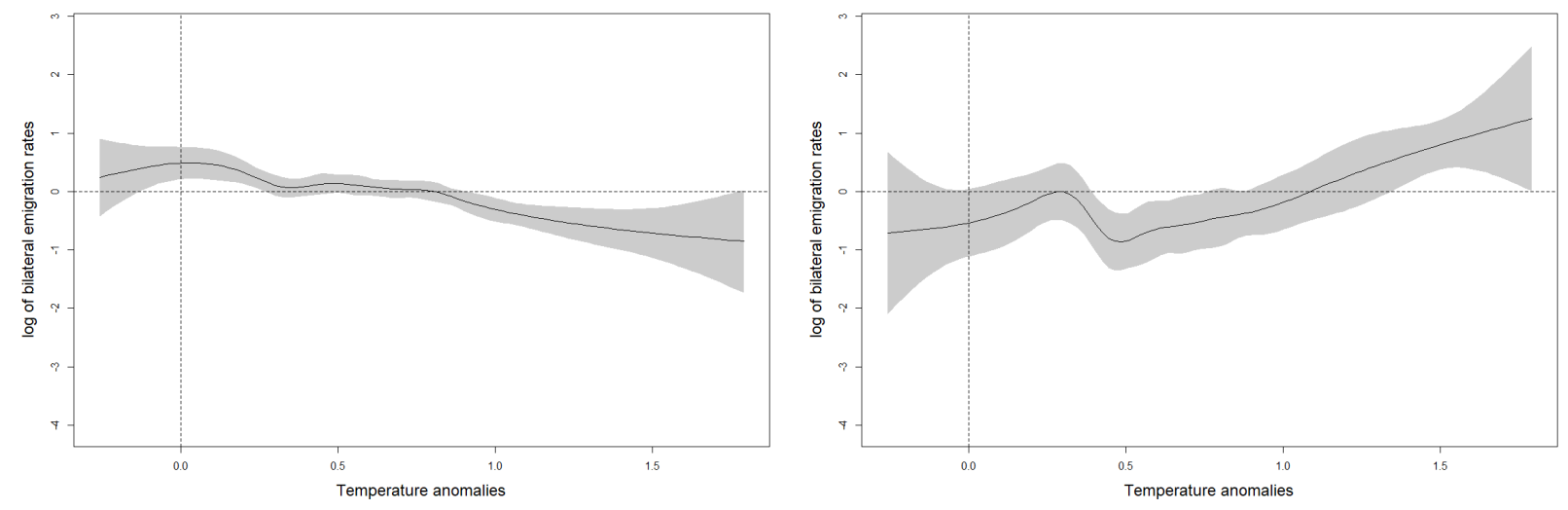

(a) Temperature and migration to non-OECD countries

(b) Temperature and migration to OECD countries
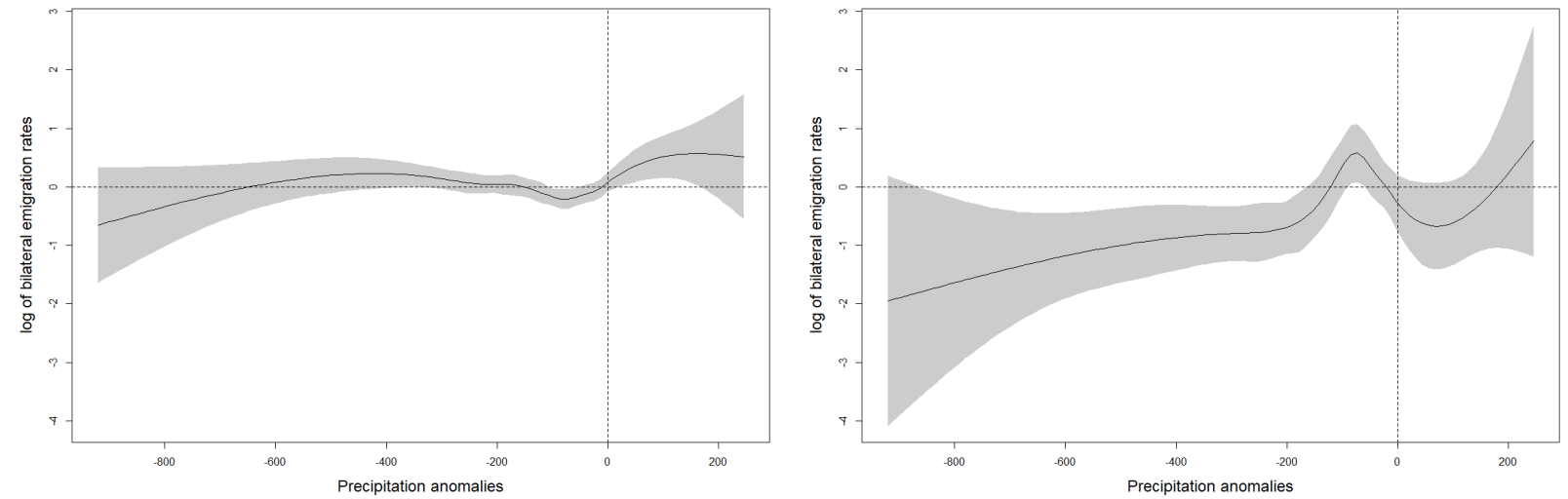

(c) Precipitation and migration to non-OECD countries

(d) Precipitation and migration to OECD countries

Figure 6: Nonlinear effects of temperature and precipitation anomalies on migration from middle-income countries to OECD and non-OECD countries 
where $O E C D_{j}$ is a dummy variable that equals one if destination $j$ is an OECD country and zero otherwise.

Table 4 presents the regression results. For low-income countries, relationships between climatic anomalies and migration show differing degrees of nonlinearity for OECD and nonOECD destination countries: While edf of 8.5 and 8.6 for the respective smooth terms of temperature and precipitation anomalies are comparable to those found in the main results in Table 2, edf for the corresponding OECD interaction terms are markedly lower at 4.3 and 6.4, with the latter not being statistically significant. In contrast, all smooth terms for middle-income countries are statistically significant with edf between 7.7 and 8.4.

Figures 5 and 6 plot the estimated effects of climatic anomalies on migration to OECD and non-OECD destination countries for low- and middle-income countries, respectively. For low-income countries, the relationships between temperature and precipitation anomalies and migration to non-OECD countries in Figures 5a and 5c, respectively, closely resemble the effects found in my main results (see Figures $2 \mathrm{a}$ and $2 \mathrm{~b}$ ). This suggests that climate change-induced international migration from low-income countries occurs primarily to other low- and middle-income countries, which is consistent with recent literature (e.g., Hoffmann et al. 2020). Figure 5b shows a similarly hump-shaped relationship between temperature anomalies and migration to OECD countries, which overall suggests that increases in average temperature past certain thresholds constrain migration from low-income countries to both types of destination countries.

Likewise, for middle-income countries the relationships between climatic anomalies and migration to non-OECD destination countries shown in Figures $6 \mathrm{a}$ and $6 \mathrm{c}$ are very similar to those estimated in my main results (see Figures $2 \mathrm{c}$ and $2 \mathrm{~d}$ ). Interestingly, I find a positive effect of temperature anomalies on migration to OECD countries (see Figure 6b), whereas shortages in precipitation appear to decrease migration to OECD countries (see Figure 6d). This finding is in contrast to Cattaneo and Peri (2016) who find no effect of temperature and precipitation on migration from middle-income countries to OECD countries. Overall, 
the results again are inconsistent with the migration patterns predicted by the real-options framework.

\section{Robustness Checks}

For my empirical analysis I followed Cattaneo and Peri (2016) and Beine and Parsons (2017) in defining countries in the bottom quartile of the GDP per capita distribution as "low-income countries". Nevertheless, this delineation inevitably involves some arbitrariness since there is no clear definition of what a low-income country is, and thus a potential concern is that varying the threshold between low- and middle-income countries may yield differing results. To address this concern, I repeat my analysis using the 20th and 30th percentile of the GDP per capita distribution as alternative thresholds.

The results are presented in Table 5 in the appendix. For both alternative thresholds, the edf estimated by the GAM are of similar magnitude compared to the main results. Turning to the plots of the estimated effects in Figures 7 and 8 , I find very similar relationships compared to the main results when using the 30th percentile of the income distribution as the threshold between low- and middle-income countries. The relationships estimated using the 20th percentile threshold are generally similar to the main results as well. Note, however, that instead of the flat relationship estimated previously, I now find a negative

effect of temperature anomalies on migration from middle-income countries (see Figure 7c). This suggests that the negative effects on migration from middle-income countries become larger if more countries toward the bottom end of the income distribution are included, which is in line with the idea that liquidity constraints are hindering migration from low-income countries. In addition, the negative effect of precipitation anomalies on migration from lowincome countries at the lower end of the data range in Figure $7 \mathrm{~b}$ appears somewhat more pronounced than in Figure $3 \mathrm{~b}$.

Another potential concern is that the results may be affected by the choice of the smooth- 
ing parameter selection method. While likelihood-based methods such as REML tend to exhibit faster convergence of smoothing parameters to their optimal values than prediction error-based methods such as generalized cross validation (GCV) (Wood 2011), they have also been shown to have a tendency to undersmooth, i.e. choose a too complex model (Wahba 1985; Kauermann 2005). Therefore, I reestimate Equation (12) using GCV rather than REML. As shown in Table 6 and Figure 9 in the appendix, the results are very similar to my main findings, with the exception of precipitation anomalies in middle-income countries, for which the GAM estimates somewhat higher edf; even so, the effect remains statistically insignificant.

\section{Conclusions}

The potential impact of climate change on international migration patterns has recently received considerable attention in both the public and academic debate. Yet, much of the empirical literature fails to find increases in international migration due to climate change. In light of this evidence, the current paper theoretically and empirically investigates why climate change-induced international migration appears to be relatively uncommon. Drawing on recent contributions by Gardner and Hendrickson (2018) and Mense (2018), the current paper presents an application of the real-options framework in which individuals may decide to postpone their migration response to climate change due to the fixed cost of migration as well as the option value of waiting. This framework implies that individuals choose a threshold level of quality of climatic conditions and migrate only once climatic conditions have deteriorated past this critical point.

I test this prediction empirically by estimating generalized additive models, which allow me to assess the threshold effects suggested by this theoretical framework. For low-income countries, I find a hump-shaped relationship between temperature anomalies and migration rates; this effect appears to be primarily driven by migration to other low- and middle- 
income countries. For middle-income countries, no effects of temperature and precipitation anomalies on migration rates can be observed.

I generally find no evidence of the threshold effects suggested by the real-options framework. Rather, consistent with recent literature (e.g., Cattaneo and Peri 2016; Beine and Parsons 2017; Gröschl and Steinwachs 2017; Cui and Feng 2020), the findings suggest that in low-income countries, individuals' migration response is hampered by the existence of liquidity constraints. These are likely to become more binding due to climate change-induced decreases in agricultural productivity.

A key implication of my findings is that instead of attempting to deter migration from areas increasingly affected by the impacts of climate change, policymakers should focus on both fostering migration and assisting "trapped" populations by facilitating alternative adaptation strategies. Such strategies may include shifting planting dates and planting crop varieties with different maturation periods (McCord et al. 2018), investing in irrigation systems (Benonnier, Millock and Taraz 2019) as well as cash transfer and social protection programs (Chort and de la Rupelle 2017; Mueller et al. 2020).

Finally, a number of potential directions for future research emerge from my results. First, while my findings do not support the view that the observed relative absence of climate change-induced international migration can be explained by the real-options framework, the measures of climatic anomalies used in this paper may only imperfectly capture the effects of climate change on local living conditions. Future research should thus consider applying the real-options framework to other aspects of the climate-migration relationship, such as the impact of fast-onset events such as flooding, storms and wildfire as well as the prevalence of infectious diseases (Marchiori, Maystadt and Schumacher 2012). Second, the current paper demonstrates how semiparametric estimation methods can be applied to assess nonlinearities in the relationship between climate and international migration. This methodology could be easily utilized by future research to investigate other determinants of international migration patterns. 


\section{References}

Abadie, L.M., E. Sainz de Murieta and I. Galarraga (2017), Investing in adaptation: Flood risk and real option application to Bilbao, Environmental Modelling and Software 95, 76-89.

Abel, G.J. and N. Sander (2014), Quantifying global international migration flows, Science $343,1520-1522$.

Anam, M., S.-H. Chiang and L. Hua (2008), Uncertainty and international migration: An option cum portfolio model, Journal of Labor Research 29, 236-250.

Baez, J., G. Caruso, V. Mueller and C. Niu (2017a), Droughts augment youth migration in Northern Latin America and the Caribbean, Climatic Change 140, 423-435.

Baez, J., G. Caruso, V. Mueller and C. Niu (2017b), Heat exposure and youth migration in Central America and the Caribbean, American Economic Review: Papers \& Proceedings $107,446-450$.

Barrios, S., L. Bertinelli and E. Strobl (2006), Climatic change and rural-urban migration: The case of Sub-Saharan Africa, Journal of Urban Economics 60, 357-371.

Basile, R. and J. Lim (2006), Wages differentials and interregional migration in the U.S.: An empirical test of the "option value of waiting" theory, 46th Congress of the European Regional Science Association: "Enlargement, Southern Europe and the Mediterranean", August 30 - September 3, 2006, Volos, Greece, European Regional Science Association (ERSA), Louvain-la-Neuve.

Basile, R. and J. Lim (2017), Nonlinearities in interregional migration behavior: Evidence from the United States, International Regional Science Review 40, 563-589.

Beine, M., I. Noy and C. Parsons (2021), Climate change, migration and voice, Climatic Change 167:8, https://doi.org/10.1007/s10584-021-03157-2 
Beine, M. and C. Parsons (2015), Climatic factors as determinants of international migration, Scandinavian Journal of Economics 117, 723-767.

Beine, M. and C. Parsons (2017), Climatic factors as determinants of international migration: Redux, CESifo Economic Studies 63, 386-402.

Benonnier, T., K. Millock and V. Taraz (2019), Climate change, migration and irrigation, Paris School of Economics Working Paper No. 2019-21, Paris School of Economics, Paris.

Bertoli, S., F. Docquier, H. Rapoport and I. Ruyssen (2020), Weather shocks and migration intentions in Western Africa: Insights from a multilevel analysis, CESifo Working Paper No. 8064, Center for Economic Studies and ifo Institute (CESifo), Munich.

Burda, M.C. (1995), Migration and the option value of waiting, The Economic and Social Review 27, 1-19.

Burda, M.C., W. Härdle, M. Müller and A. Werwatz (1998), Semiparametric analysis of German East-West migration intentions: Facts and theory, Journal of Applied Econometrics $13,525-541$.

Burzynski, M., C. Deuster, F. Docquier and J. de Melo (2019), Climate change, inequality, and human migration, IZA Discussion Paper No. 12623, Institute of Labor Economics (IZA), Bonn.

Cai, R., S. Feng, M. Oppenheimer and M. Pytlikova (2016), Climate variability and international migration: The importance of the agricultural linkage, Journal of Environmental Economics and Management 79, 135-151.

Cattaneo, C., M. Beine, C.J. Fröhlich, D. Kniveton, I. Martinez-Zarzoso, M. Mastrorillo, K. Millock, E. Piguet and B. Schraven (2019), Human migration in the era of climate change, Review of Environmental Economics and Policy 13, 189-206. 
Cattaneo, C. and V. Bosetti (2017), Climate-induced international migration and conflict, CESifo Economic Studies 63, 500-528.

Cattaneo, C. and G. Peri (2016), The migration response to increasing temperatures, Journal of Development Economics 122, 127-146.

Chort, I. and M. de la Rupelle (2017), Managing the impact of climate change on migration: Evidence from Mexico, GLO Discussion Paper No. 78, Global Labor Organization, Maastricht.

Cui, X. and S. Feng (2020), Climate change and migration, in: K.F. Zimmermann (ed.), Handbook of Labor, Human Resources and Population Economics, Springer, Cham, Switzerland.

Dell, M., B.F. Jones and B.A. Olken (2014), What do we learn from the weather? The new climate-economy literature, Journal of Economic Literature 52, 740-798.

Dixit, A.K. (1992), Investment and hysteresis, Journal of Economic Perspectives 6, 107-132.

Dixit, A.K. and R.S. Pindyck (1994), Investment under Uncertainty, Princeton University Press, Princeton, NJ.

Drabo, A. and L.M. Mbaye (2015), Natural disasters, migration and education: An empirical analysis in developing countries, Environment and Development Economics 20, 767-796.

Feenstra, R.C., R. Inklaar and M.P. Timmer (2015), The next generation of the Penn World Table, American Economic Review 105, 3150-3182.

Gardner, J. and J.R. Hendrickson (2018), If I leave here tomorrow: An option view of migration when labor market quality declines, Southern Economic Journal 84, 786-814.

Ginbo, T., L. Di Corato and R. Hoffmann (2021), Investing in climate change adaptation and mitigation: A methodological review of real-options studies, Ambio 50, 229-241. 
Gray, C. and V. Mueller (2012), Natural disasters and population mobility in Bangladesh, Proceedings of the National Academy of Sciences 109, 6000-6005.

Gröschl, J. and T. Steinwachs (2017), Do natural hazards cause international migration?, CESifo Economic Studies 63, 445-480.

Harris., I., T.J. Osborn, P. Jones and D. Lister (2020), Version 4 of the CRU TS monthly high-resolution gridded multivariate climate dataset, Scientific Data 7:109, https://doi.org/10.1038/s41597-020-0453-3

Hastie, T. and R. Tibshirani (1986), Generalized additive models, Statistical Science 1, 297-318.

Henderson, J.V., A. Storeygard and U. Deichmann (2017), Has climate change driven urbanization in Africa?, Journal of Development Economics 124, 60-82.

Hoffmann, R., A. Dimitrova, R. Muttarak, J.C. Cuaresma and J. Peisker (2020), A metaanalysis of country-level studies on environmental change and migration, Nature Climate Change 10, 904-912.

Intergovernmental Panel on Climate Change (2014), Climate Change 2014: Impacts, Adaptation, and Vulnerability. Part A: Global and Sectoral Aspects. Contribution of Working Group II to the Fifth Assessment Report of the Intergovernmental Panel on Climate Change, in: Field, C.B., V.R. Barros, D.J. Dokken, K.J. Mach, M.D. Mastrandrea, T.E. Bilir, M. Chatterjee, K.L. Ebi, Y.O. Estrada, R.C. Genova, B. Girma, E.S. Kissel, A.N. Levy, S. MacCracken, P.R. Mastrandrea, and L.L.White (eds.), Cambridge University Press, Cambridge, UK and New York, NY.

International Monetary Fund (2021), World Economic Outlook Database, April 2021 edition, https://www.imf.org/en/Publications/WEO/weo-database/2021/April 
Kauermann, G. (2005), A note on smoothing parameter selection for penalized spline smoothing, Journal of Statistical Planning and Inference 127, 53-69.

Marchiori, L., J.-F. Maystadt and I. Schumacher (2012), The impact of weather anomalies on migration in Sub-Saharan Africa, Journal of Environmental Economics and Management $63,355-374$.

Marra, G. and S.N. Wood (2012), Coverage properties of confidence intervals for generalized additive model components, Scandinavian Journal of Statistics 39, 53-74.

McCord, P., K. Waldman, E. Baldwin, J. Dell'Angelo and T. Evans (2018), Assessing multi-level drivers of adaptation to climate variability and water insecurity in smallholder irrigation systems, World Development 108, 296-308.

Mense, A. (2018), A real options approach to amenity valuation: The role of uncertainty and risk aversion, Journal of Regional Science 58, 315-329.

Millock, K. (2015), Migration and environment, Annual Review of Resource Economics 7, $35-60$.

Moretto, M. and S. Vergalli (2008), Migration dynamics, Journal of Economics 93, 223-265.

Mueller, V., C. Gray, S. Handa and D. Seidenfeld (2020), Do social protection programs foster short-term and long-term migration adaptation strategies?, Environment and Development Economics 25, 135-158.

Mueller, V., C. Gray and K. Kosec (2014), Heat stress increases long-term human migration in rural Pakistan, Nature Climate Change 4, 182-185.

Myers, N. (2005), Environmental refugees: An emergent security issue, 13th Economic Forum, Prague, May 23-27 2005, Organization for Security and Co-operation in Europe.

O'Connell, P.G.J. (1997), Migration under uncertainty: "Try your luck" or "wait and see", Journal of Regional Science 37, 331-347. 
Oezden, C., C.R. Parsons, M. Schiff and T.L. Walmsley (2011), Where on earth is everybody? The evolution of global bilateral migration 1960-2000, World Bank Economic Review $25,12-56$.

Ortega, F. and G. Peri (2013), The effect of income and immigration policies on international migration, Migration Studies 1, 47-74.

Ruyssen, I. and G. Rayp (2014), Determinants of intra-regional migration in Sub-Saharan Africa 1980-2000, Journal of Development Studies 50, 426-443.

Stern, N. (2006), The Economics of Climate Change: The Stern Review, Cambridge University Press, Cambridge, UK and New York, NY.

Stinnett, D.M., J. Tir, P. Schafer, P.F. Diehl and C. Gochman (2002), The Correlates of War project Direct Contiguity data, version 3, Conflict Management and Peace Science 19, $59-67$.

United Nations (2013), Trends in International Migrant Stock: The 2013 Revision - Migrants by Destination and Origin, Department of Economic and Social Affairs, Population Division, New York, NY.

Vezzoli, S., M. Villares-Varela and H. de Haas (2014), Uncovering international migration flow data: Insights from the DEMIG databases, IMI Working Paper No. 88, International Migration Institute, Oxford.

Wahba, G. (1985), A comparison of GCV and GML for choosing the smoothing parameter in the generalized spline smoothing problem, The Annals of Statistics 13, 1378-1402.

Wesselbaum, D. and A. Aburn (2019), Gone with the wind: International migration, Global and Planetary Change 178, 96-109.

Wood, S.N. (2001), mgcv: GAMs and generalized ridge regression for R, R News 1, 20-25. 
Wood, S.N. (2011), Fast stable restricted maximum likelihood and marginal likelihood estimation of semiparametric generalized linear models, Journal of the Royal Statistical Society 73, 3-36.

Wood, S.N. (2017), Generalized Additive Models: An Introduction with R, Chapman and Hall, Boca Raton, FL.

World Bank (2021), World Development Indicators, https://databank.worldbank.org/source/world-development-indicators 


\section{Appendix}

Table 5: Robustness checks: alternative definitions of low-income country

\begin{tabular}{|c|c|c|c|c|}
\hline \multirow[b]{2}{*}{ Smooth terms } & \multicolumn{2}{|c|}{ Bottom $20 \%$} & \multicolumn{2}{|c|}{ Bottom $30 \%$} \\
\hline & $\begin{array}{c}(1) \\
\text { Low-income countries } \\
\text { edf }\end{array}$ & $\begin{array}{c}(2) \\
\text { Middle-income countries } \\
\text { edf }\end{array}$ & $\begin{array}{c}(3) \\
\text { Low-income countries } \\
\text { edf }\end{array}$ & $\begin{array}{c}(4) \\
\text { Middle-income countries } \\
\text { edf }\end{array}$ \\
\hline $\mathrm{s}(\mathrm{T})$ & $\begin{array}{c}8.931^{* * *} \\
(0.000)\end{array}$ & $\begin{array}{l}7.744^{* * *} \\
(0.0012)\end{array}$ & $\begin{array}{c}8.631^{* * *} \\
(0.000)\end{array}$ & $\begin{array}{c}8.475^{* *} \\
(0.018)\end{array}$ \\
\hline $\mathrm{s}(\mathrm{P})$ & $\begin{array}{c}8.284^{* * *} \\
(0.000)\end{array}$ & $\begin{array}{c}7.326 \\
(0.101)\end{array}$ & $\begin{array}{c}8.781^{* * * *} \\
(0.001)\end{array}$ & $\begin{array}{c}7.990^{* *} \\
(0.018)\end{array}$ \\
\hline REML score & -170292.6 & -593471 & -249423 & -518768.2 \\
\hline $\mathrm{AIC}$ & -340598 & -1187258 & -498951.8 & -1037842 \\
\hline $\mathrm{N}$ & 21060 & 86580 & 31980 & 75660 \\
\hline Pseudo-R ${ }^{2}$ & 0.565 & 0.400 & 0.535 & 0.437 \\
\hline
\end{tabular}

Note: Time period: 1990-2010. Approximate p-values in parentheses. edf: effective degrees of freedom, REML: restricted maximum likelihood, AIC: Akaike information criterion. ${ }^{*} p<0.1,{ }^{* *} p<0.05,{ }^{* * *} p<0.01$.

Table 6: Robustness checks: smoothing parameter selection using GCV

(1)

(2)

Smooth terms Low-income countries Middle-income countries

\begin{tabular}{lcc} 
& $e d f$ & $e d f$ \\
\hline $\mathrm{s}(\mathrm{T})$ & $8.826^{* * *}$ & $7.465^{* *}$ \\
& $(0.000)$ & $(0.033)$ \\
$\mathrm{s}(\mathrm{P})$ & $8.806^{* * *}$ & 8.840 \\
& $(0.000)$ & $(0.104)$ \\
$\mathrm{GCV}$ score & 5.523 & 6.043 \\
$\mathrm{AIC}$ & -381210.7 & -888150.4 \\
$\mathrm{~N}$ & 26520 & 81120 \\
Pseudo-R & 0.541 & 0.415 \\
\hline
\end{tabular}

Note: Time period: 1990-2010. Approximate p-values in parentheses. edf: effective degrees of freedom, REML: restricted maximum likelihood, AIC: Akaike information criterion. ${ }^{*} p<0.1,{ }^{* *} p<0.05,{ }^{* * *} p<0.01$. 


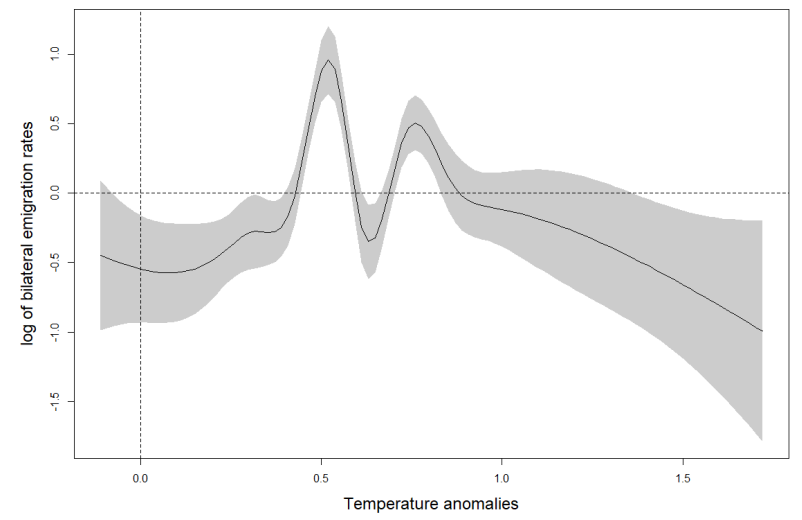

(a) Temperature, low-income countries

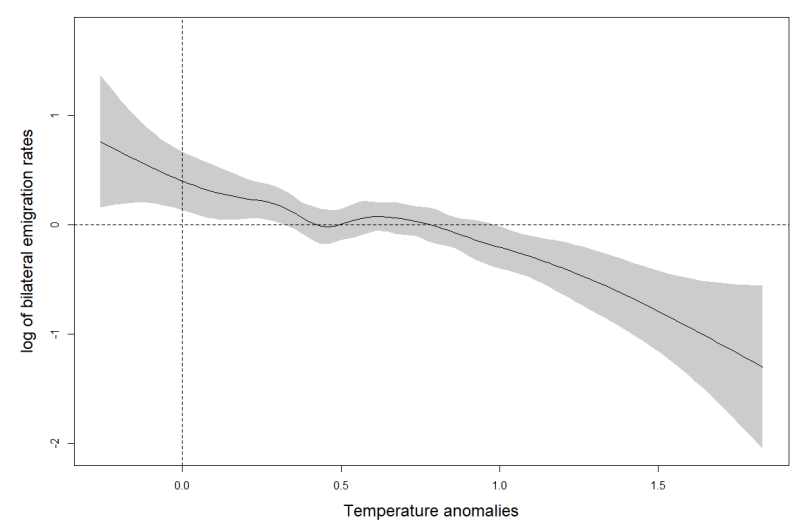

(c) Temperature, middle-income countries

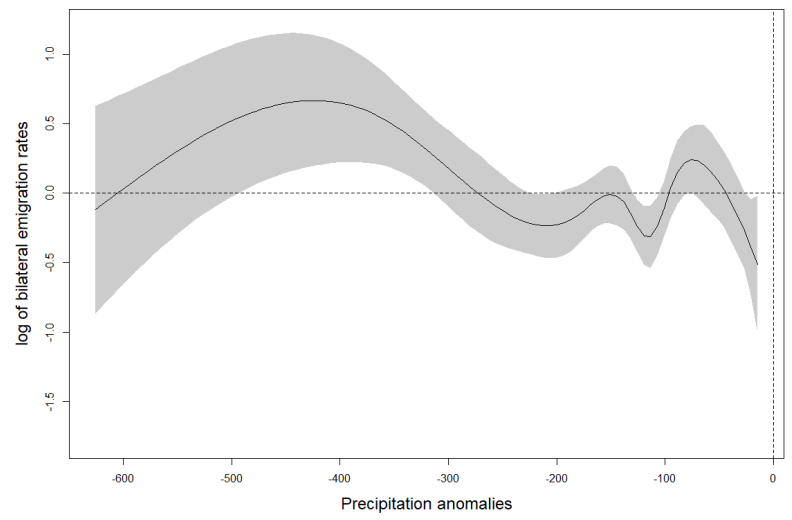

(b) Precipitation, low-income countries

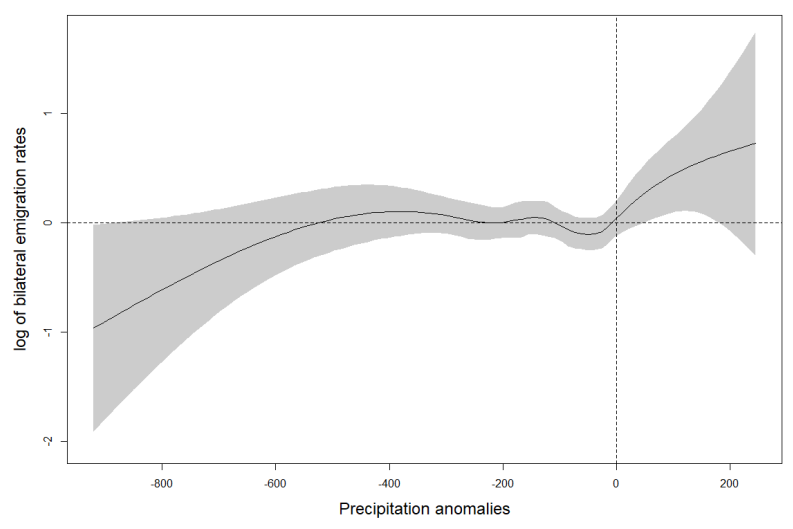

(d) Precipitation, middle-income countries

Figure 7: Nonlinear effects of temperature and precipitation anomalies on migration: defining the bottom $20 \%$ of the income distribution as low-income countries 


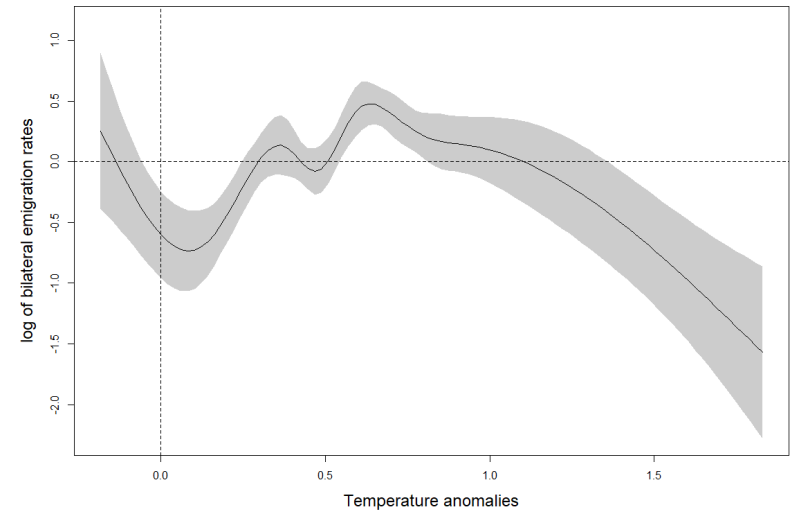

(a) Temperature, low-income countries

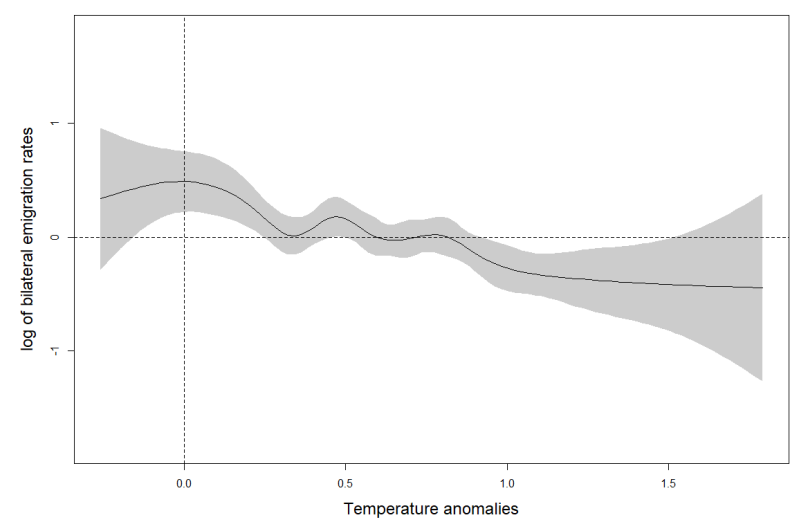

(c) Temperature, middle-income countries

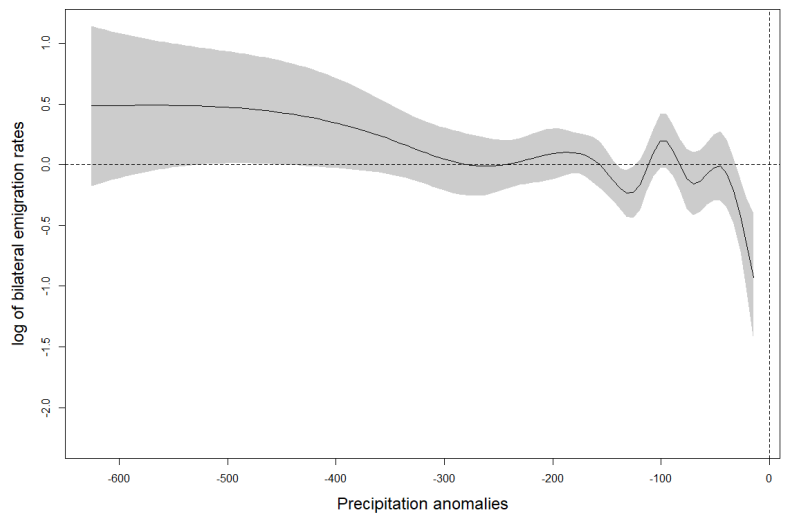

(b) Precipitation, low-income countries

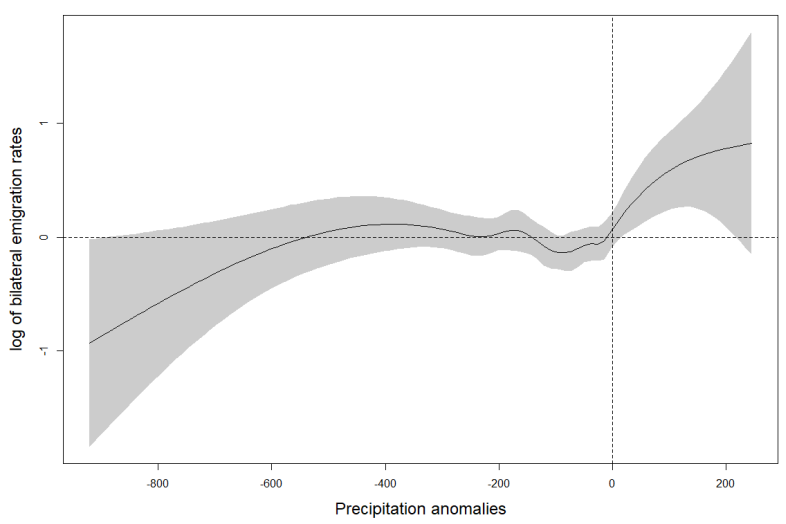

(d) Precipitation, middle-income countries

Figure 8: Nonlinear effects of temperature and precipitation anomalies on migration: defining the bottom $30 \%$ of the income distribution as low-income countries 


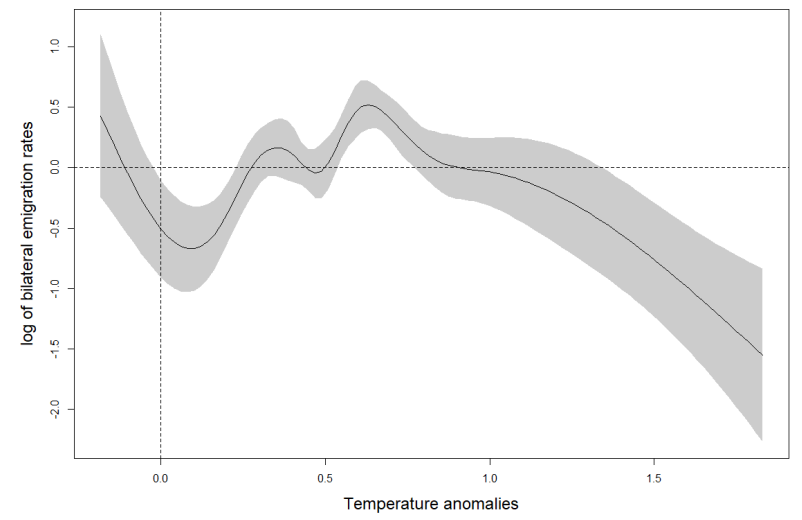

(a) Temperature, low-income countries

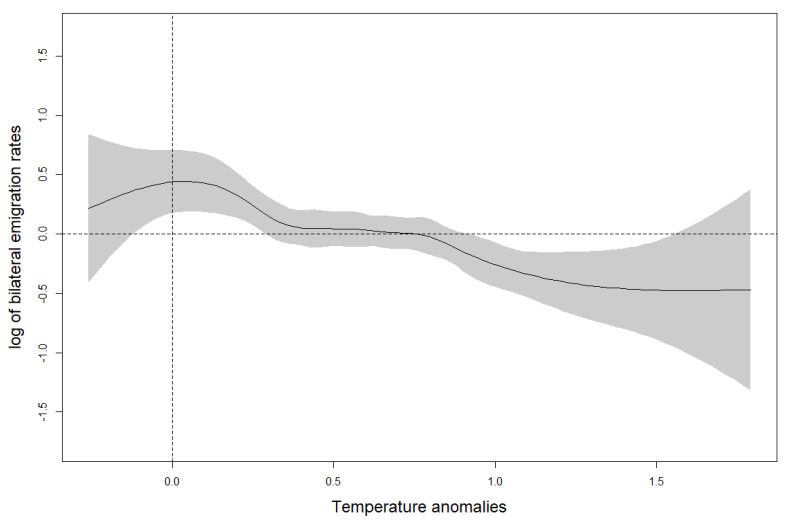

(c) Temperature, middle-income countries

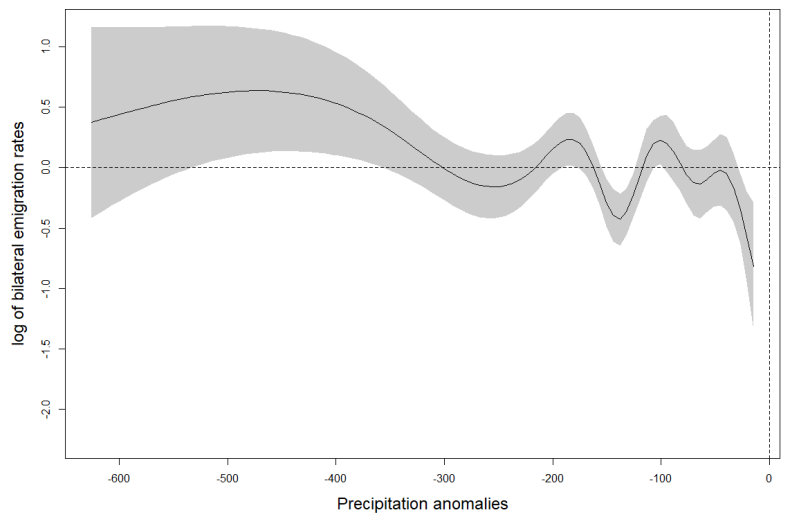

(b) Precipitation, low-income countries

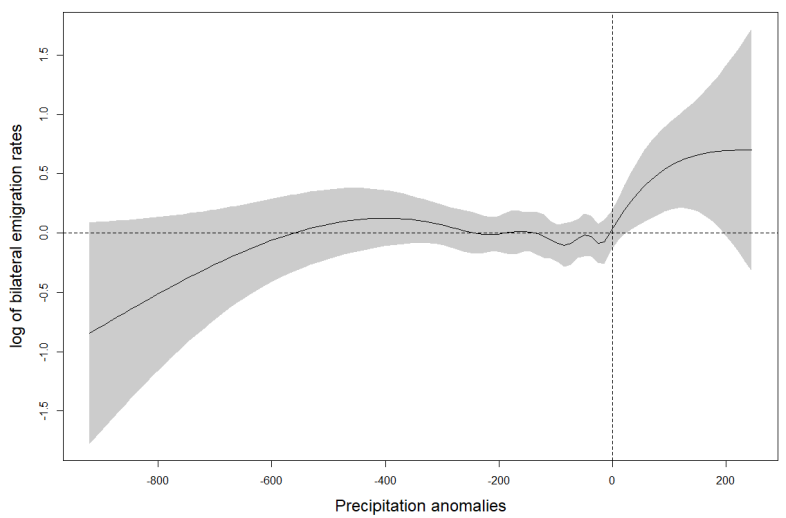

(d) Precipitation, middle-income countries

Figure 9: Nonlinear effects of temperature and precipitation anomalies on migration: smoothing parameter selection using GCV 


\section{List of low-income countries}

Bangladesh, Bosnia-Herzegovina, Burkina Faso, Burundi, Cambodia, Cape Verde, Central African Republic, Chad, China, Democratic Republic of Congo, Equatorial Guinea, Ethiopia, Guinea, India, Lesotho, Liberia, Madagascar, Malawi, Mali, Mozambique, Myanmar, Nepal, Niger, Rwanda, Sao Tome and Principe, Sierra Leone, South Sudan, Sudan, Syria, Tanzania, Togo, Uganda, Vietnam, Yemen

\section{List of middle-income countries}

Albania, Algeria, Angola, Argentina, Armenia, Azerbaijan, Bahamas, Bahrain, Barbados, Belarus, Belize, Benin, Bhutan, Bolivia, Botswana, Brazil, Brunei, Bulgaria, Cameroon, Comoros, Costa Rica, Croatia, Cyprus, Djibouti, Dominican Republic, Ecuador, Egypt, El Salvador, Fiji, Gabon, Gambia, Georgia, Ghana, Grenada, Guatemala, Guinea Bissau, Guyana, Haiti, Honduras, Hong Kong, Indonesia, Iran, Iraq, Ivory Coast, Jamaica, Jordan, Kazakhstan, Kenya, Kuwait, Kyrgyzstan, Laos, Lebanon, Libya, Macao, Macedonia, Malaysia, Maldives, Malta, Mauritania, Mauritius, Moldova, Mongolia, Montenegro, Morocco, Namibia, Nicaragua, Nigeria, Oman, Pakistan, Panama, Papua New-Guinea, Paraguay, Peru, Philippines, Puerto Rico, Qatar, Republic of Congo, Romania, Russia, Samoa, Saudi Arabia, Senegal, Serbia, Singapore, Solomon Islands, South Africa, South Korea, Sri Lanka, Suriname, Swaziland, Tajikistan, Thailand, Tonga, Trinidad and Tobago, Tunisia, Turkmenistan, Ukraine, United Arab Emirates, Uruguay, Uzbekistan, Vanuatu, Venezuela, Zambia, Zimbabwe 